Editorial

\title{
Quality and democraticity in scientific dissemination
}

\section{Editorial}

Presently, there is a reinforcement of the importance of Sociology in the thinking of society, as well as for society to think of itself. This takes place in a scenario of globalisation, in which there is an increasingly narrow and visible influence between the various societies and cultures, which seem increasingly fragmented. Sociology International Journal (SIJ) emerges in this context, where the production and dissemination of rigorous and controlled sociological knowledge at its various levels-micro, meso and macro-sociologicalare found to be paramount.

SIJ aims to fulfil the purpose of being a means through which researchers, in their diversity, may disseminate the results of their research and reflections, adding to a greater democraticity in publication, always valuing, as a critical element, the quality of the manuscript. So as to fulfil this purpose, SIJ is composed of a high-quality editorial board and reviewers, in the respect for the plurality of Sociology worldwide that, in its assessments of submitted manuscripts, seeks to contribute, in a constructive way, to the improvement of its quality. We invite you to browse $S I J$, which, being a recent journal, seeks to maintain and foster its scientific credibility and its international impact, in the respect for the trust placed in us by all authors who have already submitted, as well as the many who will submit manuscripts for possible publication in SIJ.
Volume 2 Issue 5 - 2018

\author{
Sandro Serpa \\ Department of sociology, University of the Azores, Portugal
}

Correspondence: Sandro Serpa, University of the Azores, Faculty of Social and Human Sciences, Department of Sociology, Interdisciplinary Centre of Social Sciences -CICS. UAc/CICS.NOVA.UAc, Interdisciplinary Centre for Childhood and Adolescence-NICA-UAc, Ponta Delgada, Portugal,Tel 351964424554, Email sandro.nf.serpa@uac.pt

Received: October 09, 2018 | Published: October 10, 2018

\section{Acknowledgements}

None.

\section{Conflict of interest}

The author declares that there is no conflict of interest. 